\title{
ESTUDIO COMPARATIVO DE LA OZONIZACIÓN DE ACEITES DE GIRASOL MODIFICADOS GENÉTICAMENTE Y SIN MODIFICAR
}

\author{
Maritza F. Díaz Gómez*, Oscar E. Ledea Lozano y Magali Gómez Regüeiferio \\ Centro de Investigaciones del Ozono, Apartado 6412, Ciudad de La Habana, Cuba \\ Rafael Garcés Mancheño, Manuel S. Alaiz Barragán y Enrique Martínez Force \\ Instituto de la Grasa, Consejo Superior de Investigaciones Científicas, Sevilla, España
}

Recebido em 2/3/09; aceito em 19/5/09; publicado na web em 20/10/09

\begin{abstract}
COMPARATIVE STUDY OF THE OZONATION OF GENETICALLY MODIFIED AND NOT MODIFIED SUNFLOWER OILS. Ozonation of sunflower oils with genetic modification High Oleic and High Oleic-Palmitic (AO and PO respectively) and without modification, High Linoleic (AL) at different applied ozone dosages was carried out with measurement of peroxide and acidity indexes values, fatty acids composition, oxygen percentage content and antimicrobial activity. The comparison of peroxides indexes and oxygen content at different applied ozone dosages in each oil showed good correlation $(r=0,99)$. Higher amount of oleic acid was consumed at higher applied ozone dosage in $\mathrm{PO}$ oil than $\mathrm{AO}$ oil, which can be related to the increase of acidity index. The antimicrobial activity was better for AL and PO ozonized oils.
\end{abstract}

Keywords: ozonized sunflower modified oil; peroxides index; gas-liquid chromatography.

\section{INTRODUCCIÓN}

Los aceites son grasas vegetales que se encuentran como productos de reserva para la germinación en el interior de las células de semillas y algunos frutos. Los más habituales para el consumo humano son los obtenidos a partir de semillas y de frutos. ${ }^{1}$ El aceite de girasol es obtenido a partir de las semillas del girasol y es rico en los ácidos grasos insaturados oleico y linoleico, lo que se corresponde con casi un $90 \%$ de su composición y el resto un $10 \%$ se corresponde con los ácidos grasos saturados palmítico y esteárico. ${ }^{2}$

Los avances en la materia de genética vegetal revelan procesos bioquímicos por lo que muchas plantas producen aceites vegetales con mejores composición, estabilidad y propiedades. ${ }^{3}$ Se han utilizado procesos de mutagénesis para crear semillas de girasol especiales con modificaciones en los diferentes ácidos grasos, que influyen en las características del aceite. ${ }^{4} \mathrm{~A}$ partir de estos resultados, utilizando una metodología avanzada y rápida de análisis, pueden ser obtenidas semillas de girasol especiales, donde se acelera su evolución de forma natural y se produce variabilidad genética, proceso más rápido y con mayor precisión que las técnicas de cultivos tradicionales. ${ }^{5}$

A partir de la semilla del girasol modificada genéticamente se han obtenido aceites con diferente composición de ácidos grasos, los cuales pueden ser ricos en acido oleico de $70-90 \%{ }^{6}$ y en ácidos grasos saturados como el palmítico de un $25-30 \%,{ }^{7}$ etc.

Al hacer reaccionar una corriente de ozono con aceite de girasol calidad comestible, se forman diferentes compuestos oxigenados como ozónidos, hidroperóxidos, aldehídos, entre otros ${ }^{8}$ (Figura 1), los cuales presentan efectos germicida y parasiticida ${ }^{9,10}$ que los hacen muy útiles en el tratamiento de la epidermofitosis, impétigo y giardia lamblia. $^{11,12}$

Se han desarrollado diferentes estudios sobre la composición química y microbiológica de diferentes aceites vegetales ozonizados tales como, el girasol. ${ }^{13-16}$ Sin embargo, no hemos encontrado ningún estudio realizado en los aceites vegetales modificados genéticamente tratado con ozono, los cuales pudieran sustituir al aceite de girasol ozonizado, debido a su menor precio en el mercado. Por lo que es

*e-mail: maritza.diaz@cnic.edu.cu

\section{Ozónidos}

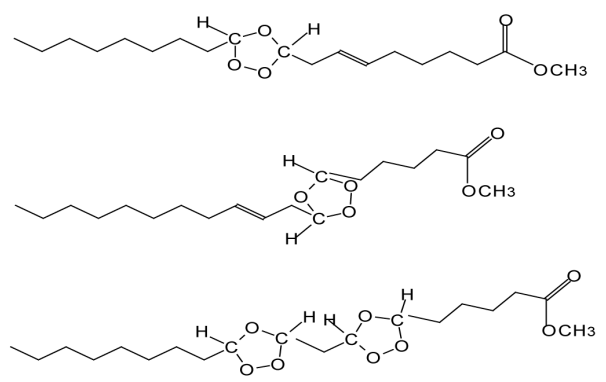

Hidroperóxidos<smiles>CCCCCCCCC(O)CO</smiles><smiles>COC(=O)CCCC/C=C/CC(O)O</smiles><smiles>COC(=O)CCCCC(O)O</smiles>

Aldehídos<smiles>CCCCCCCCC=O</smiles>

Figura 1. Algunas estructuras de ozónidos, hidroperóxidos y aldehídos obtenidas de la reacción del ozono con los triglicéridos de los aceites vegetales

objetivo de este trabajo la comparación química y microbiológica entre los aceites ozonizados de girasol sin modificar y modificados genéticamente, usando diferentes técnicas volumétricas, análisis elemental, cromatografía gaseosa, y métodos de evaluación de la 
actividad microbiana mediante dilución de agar y macrodilución para diferentes microorganismos.

\section{PARTE EXPERIMENTAL}

\section{Disolventes y reactivos}

Se utilizó aceite de girasol calidad comestible marca Ideal Argentino (AL). Los aceites de girasol modificados mediante biosíntesis, alto Palmítico-Oleico (PO) y alto Oleico (AO) fueron elaborados en el Instituto de la Grasa, Sevilla, España. Los reactivos ácido acético glacial, cloroformo, yoduro de potasio, almidón, tiosultafo de sodio, hidróxido de potasio, fenolftaleina, éter, etanol fueron calidad puro para análisis de la firma Merck, Alemania.

\section{Procedimiento general de ozonización}

Un volumen de $150 \mathrm{~mL}$ de cada aceite fue colocado en un reactor de burbujeo de $0,3 \mathrm{~L}$ con tapa esmerilada a temperatura de $25{ }^{\circ} \mathrm{C}$. La reacción de ozonización se realizó a las siguientes dosis de ozono aplicadas (DOA): 26; 43; y $66 \mathrm{mg} / \mathrm{g}$, durante los tiempos de reacción de 1,3; 2,5 y 4 h para los aceites modificados AO y PO, respectivamente. Mientras que para el aceite no modificado AL las dosis de ozono aplicadas fueron de 26,47 y $82 \mathrm{mg} / \mathrm{g}$ durante 1,3; 2,75 y $4,75 \mathrm{~h}$. Las muestras fueron almacenadas a $-10{ }^{\circ} \mathrm{C}$ hasta que se realizaron los posteriores análisis.

\section{Generación de ozono}

El ozono fue generado en un ozonizador Trailigaz (Labo, Francia) 12-02, mediante el paso del oxígeno a través de este a un flujo constante de $30 \mathrm{~L} / \mathrm{h}$ y un voltaje de $130 \mathrm{~V}$. La concentración inicial de ozono fue de $79 \mathrm{mg} / \mathrm{L}$, determinada mediante un equipo medidor de ozono Ozomat de la firma Anseros, Alemania.

\section{Determinación del índice de peróxidos (IP)}

Se pesaron $0,5 \mathrm{~g}$ de muestra y se mezclaron con una disolución de ácido acético glacial-cloroformo 3:2 v/v. Se añadió 0,5 mL de una solución saturada de yoduro de potasio. La mezcla se dejó reposar durante $2 \mathrm{~min}$, se añadieron $30 \mathrm{~mL}$ de agua destilada y se valoró lentamente con una disolución de tiosulfato de sodio $0,1 \mathrm{M}$, agitando de forma continua hasta la casi desaparición del color amarillo. Se añadió $5 \mathrm{~mL}$ de una disolución indicadora de almidón y se continuó la valoración hasta la desaparición del color azul.

El IP fue calculado de la expresión: ${ }^{17}$

$\mathrm{IP}=100 \mathrm{v} / \mathrm{m}$

donde $\mathrm{v}$, es el volumen en $\mathrm{mL}$ y $\mathrm{m}$ es la masa en $\mathrm{g}$ de la muestra pesada. El IP se expresa en mmol-equivalente de oxigeno activo por $\mathrm{kg}$ de muestra.

Se realizaron 3 réplicas para cada una de las muestras.

\section{Determinación del índice de acidez (IA)}

Se pesaron de 0,9 a $1,2 \mathrm{~g}$ de muestra y se mezclaron con 50 $\mathrm{mL}$ de una mezcla de iguales volúmenes de etanol $(96 \%)$ y éter. Posteriormente se adicionaron $0,5 \mathrm{~mL}$ de disolución al $1 \% \mathrm{~m} / \mathrm{v}$ de fenolftaleina en etanol (96\%). La mezcla fue valorada con una disolución de hidróxido de potasio $0,1 \mathrm{M}$, hasta que la disolución quedó débilmente rosada al menos por $15 \mathrm{~s}$.

El IA fue calculado de la expresión: ${ }^{18}$
$\mathrm{IA}=56,1(\mathrm{~V})(\mathrm{M}) / \mathrm{m}$

donde $\mathrm{v}$ es el volumen consumido en $\mathrm{mL}, \mathrm{M}$ es la molaridad de la disolución de hidróxido de potasio y m es la masa en gramos de la muestra pesada.

El IA se expresa en miligramos de hidróxido de potasio que se requieren para neutralizar los ácidos libres en un gramo de muestra.

Se realizaron 3 réplicas para cada una de las muestras.

\section{Análisis elemental}

Se utilizó un equipo de Leco CHNS-932 Corporation St. Joseph, MI, USA, simultáneo para carbono, hidrógeno, nitrógeno y azufre con inyección automática. El sistema de detección tiene cuatro detectores individuales, tres de ellos de infrarrojo de estado sólido (C, H y S) y un cuarto de conductividad térmico diferencial para $(\mathrm{N})$. Existe un sistema de dosificación de oxígeno mediante un controlador de flujo de masa con secuencia de dosificación programable para garantizar una completa combustión, con un horno de oxidación hasta 1100 ${ }^{\circ} \mathrm{C}$ con precisión en el control de $\pm 1{ }^{\circ} \mathrm{C}$ y un horno de reducción hasta $950{ }^{\circ} \mathrm{C}$ (nominal $650{ }^{\circ} \mathrm{C}$ ). Además, el sistema posee una balanza microanalítica con legibilidad de $0,001 \mathrm{mg}$ e interconectada con el microanalizador para la transferencia automática de pesadas. El sistema incluye una prensa encapsuladota para muestras líquidas Leco modelo CP-100. Se pesó $1 \mathrm{mg}$ de las muestras para el análisis. El tiempo del análisis fue menor de $180 \mathrm{~s}$ para la determinación de los cuatro elementos (C, H, N y S). El contenido de oxígeno (CO) fue determinado mediante el cálculo de la diferencia de la sumatoria de los valores de $\mathrm{C}, \mathrm{H}, \mathrm{N}$ y $\mathrm{S}$ con respecto al $100 \% .^{19}$

\section{Análisis por cromatografía gaseosa}

Fueron analizados por cromatografía gaseosa los ácidos grasos saturados e insaturados de los aceites de girasol sin modificar y modificados genéticamente no tratados y ozonizados. Para la determinación del contenido de ácidos grasos se utilizó la técnica de transesterificación, ${ }^{20}$ para ello se prepararon los ésteres metílicos en un tubo de ensayo que contenía $10 \mu \mathrm{g}$ de muestra en $0,9 \mathrm{~mL}$ de una mezcla formada por metanol-tolueno-dimetoxipropano-ácido sulfúrico (33:14:2:1 v/v) y $0,9 \mathrm{~mL}$ de heptano. Posteriormente se colocaron los tubos cerrados herméticamente en un baño de agua a $80{ }^{\circ} \mathrm{C}$ durante $1 \mathrm{~h}$. Pasado ese tiempo los tubos se retiraron, se enfriaron y se retiró la fase orgánica, colocándola en los viales del auto-inyector de $2 \mathrm{~mL}$ de capacidad y se conservaron a $-20{ }^{\circ} \mathrm{C}$ por no más de 48 h después de su preparación.

Los esteres metílicos se obtuvieron con cromatógrafo Hewlett Packard 5890 Serie II con detector de cámara de ionización FID y un autoinyector HP6890. Se utilizó una columna Supelco SP-2380 de $30 \mathrm{~m}$ de longitud con $0,32 \mathrm{~mm}$ de diámetro interno y $0,20 \mu \mathrm{m}$ de tamaño de particular. Las corridas se realizaron con una temperatura de columna de $100{ }^{\circ} \mathrm{C}(1 \mathrm{~min})$ a $8^{\circ} \mathrm{C} / \mathrm{min}$ hasta $200{ }^{\circ} \mathrm{C}$, la temperatura del inyector y del detector fue de $280^{\circ} \mathrm{C}$. El flujo de gas portador $\left(\mathrm{H}_{2}\right)$ fue de $1 \mathrm{~mL} / \mathrm{min}$ a una presión de $50 \mathrm{KPas}$. Se utilizó un volumen de inyección de $2 \mu \mathrm{L}$.

\section{Análisis microbiológico}

Se determinó la concentración mínima inhibitoria (CMI), mediante el método de dilución en agar ${ }^{21}$ y la concentración mínima bactericida $(\mathrm{CMB})$ mediante el método de macrodilución ${ }^{22}$ de los aceites de girasol ozonizados y aceites de girasol modificados ozonizados a diferentes dosis de ozono aplicadas, frente a cepas del microorganismos Staphylococcus aureus ATCC 6538, Escherichia coli ATCC 
10536, y Pseudomona aeruginosa ATCC 27853, conservadas en el laboratorio a $5{ }^{\circ} \mathrm{C}$.

\section{Análisis estadístico}

Los resultados son expresados por la media \pm la desviación estándar en cada grupo de muestra. Se aplicó análisis de regresión lineal simple a los datos de índice de peróxidos y contenido porcentual de oxígeno.

\section{RESULTADOS Y DISCUSIÓN}

El aceite de girasol (AL) se encuentra en el grupo de aceites que presentan al ácido linoleico como ácido graso mayoritario, encontrándose su contenido entre un 48-74\% del total de ácidos grasos que lo componen. ${ }^{23}$ En este caso su composición fue de aproximadamente un $58 \%$, seguido del ácido oleico con un $29 \%$ y en menor concentración los ácidos grasos saturados. Este aceite presenta un $87 \%$ de ácidos grasos insaturados en su composición (Tabla 1). Mientras que los aceites de girasol modificados genéticamente, presentan en el caso del alto oleico (AO), un $75 \%$ de ácido oleico, un $13 \%$ de linoleico y el resto de ácidos grasos saturados, siendo este aceite muy parecido al aceite de oliva que presenta una alta proporción de ácido oleico de $65-85 \% .{ }^{1} \mathrm{El}$ otro aceite de girasol modificado alto palmito-oleico (PO) presenta un 54\% de oleico y un 28\% de ácido palmítico, siendo muy parecido a la manteca de cerdo, por tener un alto contenido de ácidos grasos saturados entre $26-32 \% .^{24}$

Tabla 1. Composición porcentual de los ácidos grasos de aceite de girasol sin modificar (AL) y modificados genéticamente (AO y PO), determinados por cromatografía gaseosa

\begin{tabular}{cccc}
\hline & $\begin{array}{c}\text { AL } \\
\text { no tratado }\end{array}$ & $\begin{array}{c}\text { AO } \\
\text { no tratado }\end{array}$ & $\begin{array}{c}\text { PO } \\
\text { no tratado }\end{array}$ \\
\hline $16: 0$ & $7,08 \pm 0,01$ & $4,77 \pm 0,13$ & $28,3 \pm 0,18$ \\
$16: 1$ & - & $0,385 \pm 0,02$ & $7,62 \pm 0,09$ \\
$18: 0$ & $4,35 \pm 0,10$ & $4,38 \pm 0,14$ & $2,29 \pm 0,08$ \\
$18: 1$ & $29,19 \pm 0,19$ & $75,08 \pm 0,15$ & $54,55 \pm 0,91$ \\
$18: 2$ & $58,3 \pm 0,34$ & $13,32 \pm 0,13$ & $5,33 \pm 0,03$ \\
$20: 0$ & $0,35 \pm 0,004$ & $0,423 \pm 0,01$ & $0,75 \pm 0,06$ \\
$22: 0$ & $0,72 \pm 0,07$ & $1,52 \pm 0,02$ & $1,24 \pm 0,16$ \\
\hline
\end{tabular}

AL aceite de girasol, $\mathrm{AO}$ aceite de girasol alto oleico modificado genéticamente, PO aceite de girasol alto palmítico-oleico modificado genéticamente, 16:0 ácido palmítico, 16:1 ácido palmitoleico, 18:0 ácido esteárico, 18:1 ácido oleico, 18:2 ácido linoleico, 20:0 ácido araquídico, 22:0 ácido behénico

En la Tabla 2 pueden observarse las muestras de aceite de girasol ozonizadas con diferentes dosis de ozono aplicadas, las cuales presentan índices de peróxidos crecientes en un rango de 363 a 1052 mmol-equiv/kg, según el avance de la reacción, tanto para el aceite de girasol (AL) como para los aceites de girasol modificados (PO y $\mathrm{AO})$. Este aumento en los índices de peróxidos es debido a la formación de compuestos oxigenados durante y después de la reacción de ozonización. Esto coincide con lo reportado para los aceites vegetales ozonizados como el girasol, ${ }^{13} \operatorname{coco}^{14}$ y oliva. ${ }^{15}$

Como puede observarse en la Tabla 2, a medida que avanza el proceso de ozonización de cada aceite de girasol, el aumento del índice de peróxidos con respecto a la dosis de ozono aplicada es directamente proporcional, desde la primera dosis de ozono de 23 hasta $82 \mathrm{mg} / \mathrm{g}$. Este comportamiento lineal se aprecia en las Ecuaciones 1-3 al presentar todas ellas coeficientes de correlación superiores al
Tabla 2. Parámetros físico-químicos de los tres aceites de girasol no tratados, ozonizados y modificados genéticamente

\begin{tabular}{lcccc}
\hline & $\begin{array}{c}\text { Aceite } \\
\text { no tratado }\end{array}$ & $\begin{array}{c}\text { Aceite } \\
\text { ozonizado } \\
\text { Muestra 1 }\end{array}$ & $\begin{array}{c}\text { Aceite } \\
\text { ozonizado } \\
\text { Muestra 2 }\end{array}$ & $\begin{array}{c}\text { Aceite } \\
\text { ozonizado } \\
\text { Muestra 3 }\end{array}$ \\
\hline AO y PO & 0 & 26 & 43 & 66 \\
AL & 0 & 26 & 47 & 82 \\
& Índice de Peróxidos (mmol-equiv/kg) & \\
PO & $8,5 \pm 0,1$ & $474 \pm 5$ & $676 \pm 2$ & $1011 \pm 5$ \\
AO & $9,8 \pm 0,1$ & $363 \pm 2$ & $670 \pm 1$ & $1052 \pm 3$ \\
AL & $7,9 \pm 0,1$ & $359 \pm 7$ & $645 \pm 1$ & $1030 \pm 4$ \\
& \multicolumn{4}{c}{ Índice de Acidez (mg } \\
PO & $0,18 \pm 0,08$ & $1,54 \pm 0,08$ & $2,32 \pm 0,03$ & $2,69 \pm 0,04$ \\
AO & $0,22 \pm 0,03$ & $0,96 \pm 0,06$ & $1,77 \pm 0,01$ & $1,99 \pm 0,02$ \\
AL & $0,12 \pm 0,02$ & $1,48 \pm 0,01$ & $2,49 \pm 0,02$ & $2,75 \pm 0,05$ \\
\hline
\end{tabular}

PO aceite de girasol alto palmítico-oleico modificado genéticamente, $\mathrm{AO}$ Aceite de girasol alto oleico modificado genéticamente, AL aceite de girasol.

99\% y de determinación superiores al 98\%. Esto implica una buena correlación entre el índice de peróxidos y la dosis de ozono aplicada para todos los aceites estudiados, resultando tener el mejor ajuste el aceite de girasol alto oleico modificado AO.

$\mathrm{PO}-\mathrm{IP}=55,25032+14,7613$ DOA $\left(\mathrm{r}=99,14 \%, \mathrm{r}^{2}=98,29 \%\right)(1)$ $\mathrm{AO}-\mathrm{IP}=3,82372+15,7538$ DOA $\left(\mathrm{r}=99,97 \%, \mathrm{r}^{2}=99,95 \%\right)$ $\mathrm{AL}-\mathrm{IP}=26,62703+12,4864$ DOA $\left(\mathrm{r}=99,83 \%, \mathrm{r}^{2}=99,67 \%\right)$

Desde el punto de vista práctico, fue posible aplicar mayores dosis de ozono al aceite de girasol AL que a los aceites AO y PO. Esto se debe a que el aceite de girasol ozonizado (AL) tiene como componente mayoritario al ácido linoleico y éste presenta en su estructura dos dobles enlaces, uno en el carbono 9 y otro en el carbono 12 , por lo que al tener mayor número de insaturaciones, puede recibir una mayor dosis de ozono y formar por la ruptura de ambos enlaces, mayor cantidad de compuestos oxigenados. Mientras, que los aceites de girasol modificados genéticamente AO y PO tienen como componente mayoritario el ácido oleico que tiene una sola insaturación en el carbono 9 y los compuestos oxigenados formados son por la ruptura de un solo doble enlace.

Paralelamente al aumento del índice de peróxidos, ocurre un aumento del índice de acidez en cada uno de los aceites de girasol ozonizados con respecto al aceite de girasol no tratado (Tabla 2). Este índice da una medida de la formación de ácidos carboxílicos en el medio de reacción, los cuales pueden formarse durante la reacción de ozonización producto de la descomposición de las especies peroxídicas y por oxidación de los aldehídos formados. . $^{24,25}$

Se puede observar en la Tabla 2, un aumento mayor de la acidez en los aceites de girasol ozonizado AL y el aceite de girasol modificado PO en los cuales aumenta su acidez 22 y 14 veces, al ser comparados los valores de acidez de las muestras 3 de ambos aceites, con respecto a los valores de acidez de los aceites no tratados con ozono, respectivamente. Las muestras 3 en ambos aceites, AL y PO incrementan su acidez en valores de 1,38 y 1,35 veces al ser comparadas con la muestra 3 del aceite de girasol modificado AO. Esto pudiera deberse a la naturaleza de la composición de cada aceite. Se conoce que los aceites vegetales ozonizados, de aquellos aceites que contienen ácido linoleico mayoritario en su composición, 
presentan entre los componentes volátiles de la mezcla de reacción, aldehídos y ácido saturados de 3 y 6 átomos de carbono, y monoinsaturados de 9 átomos de carbonos, propios de la estructura del ácido y del mecanismo de la ozonización. Por el contrario, producto de la ozonización de los aceites vegetales que contengan al ácido oleico como ácido graso mayoritario en su estructura, se obtendrá mayoritariamente en su fracción volátil, al aldehído y ácido saturado de 9 carbonos. ${ }^{25,26}$

Es conocido que la reacción del ozono con los aceites vegetales ocurre a través de los dobles enlaces de los ácidos grasos insaturados, por lo cual estos ácidos sufren variaciones en su concentración al reaccionar con el ozono. ${ }^{27,28}$ Los efectos de la ozonización en la variación del contenido de ácidos grasos insaturados en la muestra 3 de los tres aceites estudiados se muestra en la Tabla 3.

Tabla 3. Composición porcentual de los ácidos grasos insaturados del aceite de girasol sin modificar (AL) y de los modificados genéticamente (AO y PO) ozonizados, determinados por cromatografía gaseosa

\begin{tabular}{cccc}
\hline & $\begin{array}{c}\text { AL } \\
\text { Muestra 3 }\end{array}$ & $\begin{array}{c}\text { AO } \\
\text { Muestra 3 }\end{array}$ & $\begin{array}{c}\text { PO } \\
\text { Muestra 3 }\end{array}$ \\
\hline $16: 0$ & $15,80 \pm 0,22$ & $14,50 \pm 0,25$ & $64,29 \pm 0,09$ \\
$16: 1$ & - & $0,105 \pm 0,01$ & $3,30 \pm 0,08$ \\
$18: 0$ & $10,20 \pm 0,15$ & $11,27 \pm 0,08$ & $4,54 \pm 0,11$ \\
$18: 1$ & $27,53 \pm 0,19$ & $60,61 \pm 0,93$ & $21,97 \pm 0,10$ \\
$18: 2$ & $42,76 \pm 0,34$ & $10,19 \pm 0,10$ & $2,13 \pm 0,04$ \\
$20: 0$ & $1,19 \pm 0,18$ & $0,680 \pm 0,14$ & $1,50 \pm 0,07$ \\
$22: 0$ & $2,52 \pm 0,09$ & $2,64 \pm 0,12$ & $2,28 \pm 0,13$ \\
\hline
\end{tabular}

$\mathrm{AL}$ aceite de girasol ozonizado, $\mathrm{AO}$ aceite de girasol alto oleico modificado genéticamente ozonizado, $\mathrm{PO}$ aceite de girasol alto palmítico-oleico modificado genéticamente ozonizado, 16:0 ácido palmítico, 16:1 ácido palmitoleico, 18:0 ácido estédrico, 18:1 ácido oleico, 18:2 ácido linoleico, 20:0 ácido araquídico, 22:0 ácido behénico.

Al comparar la composición porcentual de los ácidos grasos reportados en las Tablas 1 y 3, podemos observar que el contenido de ellos, después de la ozonización, lógicamente aumenta para los ácidos grasos saturados y disminuye para los ácidos grasos insaturados. Esto se debe a que la reacción de ozonización en los aceites estudiados ocurre preferentemente a través del ácido graso insaturado mayoritario, por ejemplo, en los aceites de girasol modificados (AO y PO) ocurre a través del ácido oleico, mientras que para el aceite de girasol AL ocurre a través del ácido linoleico. En las muestras 3 de los aceites de girasol modificados ozonizados AO y PO (Tabla 3), disminuyó porcentualmente el ácido oleico 1,23 y 2,48 veces, respectivamente, mientras que para el aceite de girasol ozonizado AL, el ácido linoleico disminuyó porcentualmente 1,36 veces al ser comparados con los aceites de girasol sin y con modificación genética no tratados (Tabla 1)

Sin embargo, el aceite de girasol modificado PO tuvo un mayor consumo de dobles enlaces del ácido oleico a mayor dosis de ozono aplicada que el aceite de girasol modificado AO (Tabla 3), lo cual pudiera estar relacionado con el incremento del índice de acidez del aceite ozonizado PO (Tabla 2). Se conoce que a mayor consumo de doble enlace mayor es la formación de compuestos oxigenados por lo que la descomposición de los compuestos peroxídicos presentes en los diferentes equilibrios a ácidos, es mucho mayor dentro del sistema de reacción. ${ }^{16}$

La composición elemental del aceite de girasol sin y modificados genéticamente varía durante el proceso de ozonización (Tabla 4). Al aumentar la dosis de ozono aplicada, ocurre un incremento lineal en el contenido de oxígeno en las estructuras de las diferentes muestras de los tres aceites, lo cual puede apreciarse de las ecuaciones (4-6) al presentar todas ellas coeficientes de correlación superiores al 99\% y de determinación superiores al $98 \%$. Hay que destacar que se obtuvo un mejor ajuste en el aceite de girasol no modificado AL.

$$
\begin{aligned}
& \mathrm{PO}-\mathrm{CO}=10,5376+0,10437 \text { DOA }\left(\mathrm{r}=99,72 \%, \mathrm{r}^{2}=99,44 \%\right)(4) \\
& \mathrm{AO}-\mathrm{CO}=10,0485+0,09264 \text { DOA }\left(\mathrm{r}=99,25 \%, \mathrm{r}^{2}=98,51 \%\right)(5) \\
& \mathrm{AL}-\mathrm{CO}=11,0786+0,10339 \text { DOA }\left(\mathrm{r}=99,97 \%, \mathrm{r}^{2}=99,94 \%\right)(6)
\end{aligned}
$$

El aumento observado en la Tabla 4 para el contenido de oxígeno de las muestras 2 y 3 del aceite de girasol ozonizado sin modificar AL respecto a los obtenidos para los aceites de girasol modificados

Tabla 4. Composición elemental de los tres aceites de girasol, no tratados, ozonizados y modificados genéticamente. Los análisis presentan

\begin{tabular}{|c|c|c|c|c|c|}
\hline Muestras & Carbono & Hidrógeno & Nitrógeno & Azufre & Oxígeno \\
\hline AO no tratado & 77,20 & 12,10 & 0,379 & 0,144 & 10,18 \\
\hline AO muestra 1 & 74,86 & 12,17 & 0,450 & 0,021 & 12,50 \\
\hline AO muestra 2 & 73,66 & 12,13 & 0,573 & 0,048 & 13,58 \\
\hline AO muestra3 & 71,94 & 11,39 & 0,220 & 0,002 & 16,44 \\
\hline PO no tratado & 77,80 & 11,46 & 0,185 & 0,030 & 10,52 \\
\hline PO muestra 1 & 74,58 & 11,36 & 0,582 & 0,023 & 13,45 \\
\hline PO muestra 2 & 72,58 & 11,98 & 0,565 & 0,139 & 14,73 \\
\hline PO muestra 3 & 69,74 & 11,83 & 0,610 & 0,281 & 17,54 \\
\hline AL no tratado & 77,74 & 11,06 & 0,083 & 0,028 & 11,09 \\
\hline AL muestra 1 & 73,92 & 11,84 & 0,408 & 0,147 & 13,68 \\
\hline AL muestra 2 & 72,78 & 10,64 & 0,480 & 0,055 & 16,05 \\
\hline AL muestra 3 & 68,80 & 11,46 & 0,185 & 0,030 & 19,52 \\
\hline
\end{tabular}
una precisión de 0,001\% para el carbono; de 0,01\% para el hidrógeno y el nitrógeno y de 0,02\% para el azufre

Composición $(\%)$

$\mathrm{PO}$ aceite de girasol alto palmítico-oleico modificado genéticamente, $\mathrm{AO}$ aceite de girasol alto oleico modificado genéticamente, $\mathrm{AL}$ aceite de girasol. 
genéticamente y posteriormente ozonizados $\mathrm{AO}$ y $\mathrm{PO}$, se debe a que el aceite de girasol AL presenta mayor proporción en el contenido de ácidos grasos insaturados los cuales al reaccionar con el ozono forman mayor cantidad de compuestos oxigenados. El mayor valor de contenido de oxígeno se obtuvo para la muestra ozonizada 3 del aceite AL con un valor de (19,52\%), siendo este valor 1,77 veces mayor que el obtenido para el aceite de girasol sin tratar AL $(11,09 \%)$. Este resultado está acorde con lo esperado según el mecanismo de reacción y la estructura y composición de los aceites estudiados.

El mecanismo de Criegge, que describe el proceso de ozonización para los compuestos insaturados, plantea que durante esta reacción se forman especies peroxídicas, aldehídos, ácidos, ozónidos, peróxido de hidrógeno e hidroxihidroperóxidos, entre otros..$^{29}$ Estos productos oxigenados aumentan los índices de peróxidos, aldehído y acidez y contribuyen al aumento del contenido de oxígeno en las muestras ozonizadas sobretodo cuando tienen mayor contenido de ácidos grasos con más de una insaturación como el linoleico.

El contenido de oxígeno para las muestras 1, 2 y 3 del aceite de girasol modificado ozonizado PO es mayor que el del aceite de girasol modificado ozonizado AO (Tabla 4), lo que demuestra que en las tres muestras del aceite PO hay una mayor formación de compuestos oxigenados, lo que pudiera explicar la mayor formación de ácidos y el mayor consumo de dobles enlaces reportados en la Tablas 2 y 3 para este aceite, al ser comparado con el aceite de girasol modificado AO.

Los datos para la actividad antimicrobiana de los aceites de girasol ozonizados sin modificar (AL) y modificados genéticamente PO y AO se muestran en la Tabla 5. La actividad antimicrobiana fue mayor al aumentar los índices de peróxidos y de acidez en las muestras en cada uno de los aceites estudiados. Las muestras 1 que tienen un índice de peróxidos entre 359 y 474 mmol-equiv $/ \mathrm{kg}$ fueron las que tuvieron mayor concentración mínima inhibitoria (CMI) para todos los microorganismos, alrededor de $19 \mathrm{mg} / \mathrm{mL}$; mientras que las muestras 3 (las de mayores índice de peróxidos de 1011 a 1052 mmol-equiv $/ \mathrm{kg}$ ) fueron las que tuvieron un mejor comportamiento en su CMI disminuyendo a 4,5 mg/mL, a excepción de los microorganismos Escherichia coli y la Pseudomona aeruginosa para el aceite

Tabla 5. Actividad antimicrobiana de los tres aceites de girasol ozonizados sin y modificados genéticamente. Los valores de las Concentraciones Mínimas Inhibitorias (CMI) y las Concentraciones Mínimas Bactericidas (CMB) están expresados en (mg/mL)

\begin{tabular}{lcccccc}
$\begin{array}{l}\text { Cepas } \\
\text { Bacterianas }\end{array}$ & $\begin{array}{c}\text { Staphylococcus } \\
\text { aureus }\end{array}$ & \multicolumn{2}{c}{$\begin{array}{c}\text { Escherichia } \\
\text { coli }\end{array}$} & \multicolumn{2}{c}{$\begin{array}{c}\text { Pseudomona } \\
\text { aeruginosa }\end{array}$} \\
Aceites & CMI & CMB & CMI & CMB & CMI & CMB \\
\hline AO muestra 1 & 19 & 178 & 19 & 178 & 19 & 178 \\
AO muestra 2 & 9,5 & 178 & 19 & 178 & 19 & 178 \\
AO muestra 3 & 9,5 & 178 & 19 & 89 & 19 & 178 \\
PO muestra 1 & 19 & 22,25 & 19 & 44,5 & 19 & 89 \\
PO muestra 2 & 9,5 & 22,5 & 9,5 & 22,25 & 9,5 & 44,5 \\
PO muestra 3 & 4,5 & 22,5 & 9,5 & 11,13 & 9,5 & 22,25 \\
AL muestra 1 & 19 & 22,25 & 19 & 44,5 & 19 & 89 \\
AL muestra 2 & 9,5 & 11,13 & 9,5 & 11,13 & 9,5 & 44,5 \\
AL muestra 3 & 4,5 & 11,13 & 9,5 & 11,13 & 9,5 & 11,13 \\
\hline
\end{tabular}

AO aceite de girasol alto oleico modificado genéticamente, PO aceite de girasol alto palmítico-oleico modificado genéticamente, AL aceite de girasol. de girasol modificado AO, manteniendo el valor de $19 \mathrm{mg} / \mathrm{mL}$. Los aceites de girasol sin modificar AL y modificado PO tuvieron similar comportamiento con respecto a la CMI para cada microorganismo estudiado. De todos los microorganismos, el Staphylococcus aureus fue el más sensible en los tres aceites ozonizados estudiados, obteniéndose para las muestras 3 los valores más bajos de CMI.

La concentración mínima bactericida (CMB) tuvo un comportamiento similar en casi todas las muestras del aceite de girasol modificado $\mathrm{AO}$, el cual necesita mayor cantidad de muestra para inactivar a los microorganismos, este valor se mantuvo en el límite superior 178 $\mathrm{mg} / \mathrm{mL}$, a excepción de la muestra 3 de mayor índice de peróxidos que disminuyó a la mitad $89 \mathrm{mg} / \mathrm{mL}$ para el microorganismo Escherichia coli. Sin embargo, los aceites de girasol sin modificar AL y modificado PO tuvieron mejor comportamiento que el del aceite de girasol modificado AO. Estos disminuyeron sus CMB hasta $11,13 \mathrm{mg} / \mathrm{mL}$, a medida que aumentaron los índices de peróxidos y de acidez de cada muestra, resultando mucho mejor el aceite de girasol sin modificar AL para combatir las tres familias de microorganismos.

Se ha comprobado que al aumentar los índices de peróxidos y acidez aumenta la actividad antimicrobiana de estos aceites, siendo esta actividad mejor en los aceites de girasol AL y PO, coincidiendo estos resultados con un mayor contenido porcentual de oxígeno (Tabla 4) lo que se corresponde con un mayor contenido de compuestos oxigenados. Estos resultados responden a los reportados por diversos investigadores donde la actividad biológica de los aceites ozonizados se le atribuye a las especies oxigenadas. ${ }^{9,15}$ Actualmente, el mecanismo de acción de los aceites ozonizados sobre los microorganismos se desconoce, pero dada la naturaleza de sus principales compuestos oxigenados, es de esperar la hipótesis de que ocurran daños en las biomoléculas más sensibles como son los lípidos insaturados y las proteínas, debido al ataque oxidante de estos compuestos oxigenados a la envoltura celular de los microorganismos. ${ }^{30-32}$ Hay que destacar que estos aceites ozonizados no contaminan la atmósfera y no se ha reportado casos de resistencias bacterianas a estas sustancias, por lo que estos aceites pudieran ser utilizados en diversas infecciones graves ocurridas por estos microorganismos, en sustitución de los antibióticos convencionales.

\section{CONCLUSIONES}

Se demostró una buena relación lineal $\left(\mathrm{r}^{2}>99 \%\right)$ al aumentar la dosis de ozono aplicada durante la reacción de cada uno de los aceites de girasol sin modificación AL y con modificación genética AO y PO, ocurriendo un aumento lineal de los valores de índices de peróxidos y del contenido porcentual de oxígeno, este último demostrado por la técnica de análisis elemental.

Un incremento del índice de acidez fue observado en los tres aceites ozonizados, siendo mayores en los aceites de girasol modificado PO como en el sin modificar AL. También, se demostró mediante la técnica analítica de cromatografía gaseosa que el aceite de girasol modificado genéticamente $\mathrm{PO}$, en comparación con el aceite AO, tuvo un mayor consumo de ácido oleico a mayor dosis de ozono aplicada, lo cual coincidió con un aumento en el contenido porcentual de oxígeno, correspondiéndole una mayor formación de compuestos oxigenados, los cuales por descomposición de los peróxidos, pudieran estar relacionado con el incremento marcado de acidez en este aceite.

La actividad antimicrobiana de los aceites de girasol modificados ozonizados AO y PO y sin modificar ozonizados AL, en los microorganismos Staphylococcus aureus ATCC 6538, Escherichia coli ATCC 10536 y Pseudomona aeruginosa ATCC 27853, fue incrementada con un gradual incremento de la dosis de ozono. Este efecto fue mucho mayor para los aceites ozonizados AL y PO, coincidiendo estos resultados con un mayor contenido porcentual de oxígeno, 
por lo que tanto los aceites de girasol modificados genéticamente como los no modificados pudieran utilizarse en formulaciones para uso terapéutico.

\section{AGRADECIMIENTOS}

Al proyecto CITMA-CSIC, que facilitó el financiamiento otorgado para la realización de este trabajo.

\section{REFERENCIAS}

1. Gunstone, F.; Haewood, L.; Padley, B.; The lipid handbook, Chapman \& Hall Ed.: London, 1994, p. 57.

2. Dorell, D. G.; Vick, B. A. In Sunflower production and technology; Schneiter A A. P., ed.; Agronomy Monograph 35, ASC; CSSA and SSSA: Madison, 1997, p. 709.

3. Martínez-Force, E.; Garcés, R.; Trends Agr. 1999, 2, 13.

4. Fernández-Moya, V.; Martínez-Force, E.; Garcés R.; J. Agric. Food Chem. 2000, 48, A.

5. Regulación (EC) del Parlamento Europeo y del Consejo sobre alimentos y piensos genéticamente modificados, 22 de septiembre 2003, 1829, htpp://Europa,eu,int/comm/food/biotechnology/gmfood/index_en,htm.

6. Fernández-Martínez, J.; Mancha, M.; Osorio, J.; Garcés, R.; Euphytica 1997, 97, 113.

7. Osorio, J.; Fernández-Martínez, J.; Mancha, M.; Garcés, R.; Crop Sci. 1995, 35, 739 .

8. Díaz, M.; Gavín, J.; J. Braz. Chem. Soc. 2007, 18, 513.

9. Sechi, L. A.; Lezcano, I.; Nuñez, N.; Espim, M.; Dupre, I.; Pinna, A.; J. Appl. Microbiol., 2001, 90, 279.

10. Hernández, F.; Menéndez, S.; Rev. CENIC C. Biol. 1997, 28, 3.

11. Díaz, M.; Fernández, H.; Dennis, P.; Hernández, R.; Martínez, G.; Hernández, D.; Menéndez, S.; Ledea, O.; Gómez, M.; Renovación del Registro Oleozon ${ }^{\circledR}$ Tópico, CECMED, La Habana, Cuba, 2004, No, 1498, 536/02,039,04M, Nov.

12. Hernández, F.; Díaz, M.; Menéndez, S.; Zamora, Z.; Ledea, O.; Calunga, J. L.; Méndez, I.; Hernández, D.; Borrego, A.; González, M.; Fernández, H.; González, Y.; Jardines, D.; Molerio, J.; Dennis, P. N.; Registro Sanitario del medicamento Oleozon ${ }^{\circledR}$ Oral, CECMED, La Habana, Cuba, 2004, No, M-04-140-P01 de Agosto.
13. Díaz, M.; Gavín, J.; Ledea, O.; Hernández, F.; Alaiz, M., Garcés, R.; Ozone Sci. Eng. 2005, 27, 247.

14. Díaz, M.; Núñez, N.; Quincose, D.; Díaz, W.; Ozone Sci. Eng. 2005, $27,1$.

15. Díaz, M.; Hernández, R.; Martínez, G.; Vidal, G.; Gómez, M.; Fernández, H.; Garcés, R.; J. Braz. Chem. Soc. 2006, 17, 403.

16. Díaz, M.; Martínez, G.; Arteaga. M.; Garcés, R.; J. Am. Oil Chem. Soc. 2006, 83, 1.

17. British Pharmacopoeia; Peroxide value, London, 2000, Appendix XF, IA, IB.

18. British Pharmacopoeia; Acid value, London, 2000, Appendix XB, IA, IB.

19. Pasto, D.; Jhonson, C.; Determinación de estructuras orgánicas, Pueblo y Educación Ed: Ciudad de la Habana, 1980, p. 2.

20. Garcés, R.; Mancha, M.; Anal. Biochem. 1993, 211, 139.

21. NCCLS; Methods for Determining Bactericidal Activity of Antimicrobial Agents, $5^{\text {th }}$ ed., Approved Standard, 20, 2, 2000.

22. NCCLS; Methods for Dilution Antimicrobial Susceptibility Test for Bacteria that Grow Aerobically, $3^{\text {rd }}$ ed., Approved Standard, 19, 18, 1999.

23. Mehlenbacher, V.; Enciclopedia de la química industrial, Ed. Urmo: Bilbao, 1970, tomo 6, p. 235.

24. Robards, K.; Kerr, A.; Patsalides, E.; Analyst 1988, 113, 213.

25. Ledea, O.; Tesis de Doctor en Ciencias Químicas, Cuba, 2003.

26. Ledea, O.; Correa, T.; Escobar, M.; Rosado, A.; Moleiro, J.; Hernández, C.; Járdines, D.; Ozone Sci. Eng. 2001, 23, 121.

27. Gunstone, F. D.; Structured and modified lipids, Marcel Dekker Inc.: New York, 2001.

28. Ledea, O.; Martínez, E.; Garcés, F.; Alaiz, M.; Díaz, M.; Dobarganes, C.; Molerio, J.; Hernández, C:; Rosado, A.; Correa, T.; Rev. CENIC C. Quím. 2005, 36, (No. Especial).

29. Criegee, R.; Mechanism of Ozonolisis, $14^{\text {th }}$ ed., Angewandte Chemie Int.: England, 1975.

30. Prior, W. A.; Uppu, R. M.; J. Biol. Chem. 1993, 268, 3120.

31. Komanapalli, I. R.; Mudd, J. B.; Lau, H. S.; Toxicol. Lett. 1997, 90, 61.

32. Curtiellas, V.; Gómez, M.; Ledea, O.; Fernández, I.; Sánchez, E.; Rev. CENIC C. Quím. 2005, 36, (No. Especial). 